Document downloaded from:

http://hdl.handle.net/10251/62432

This paper must be cited as:

Francesco; Belda, E.; LAURA KVIST; Rguibi-Idrissi, H.; Monrós González, JS. (2015). Does fragmentation of wetlands affect gene flow in sympatric Acrocephalus warblers with different migration strategies?. Journal of Avian Biology. 46:577-588. doi:10.1111/jav.00589.

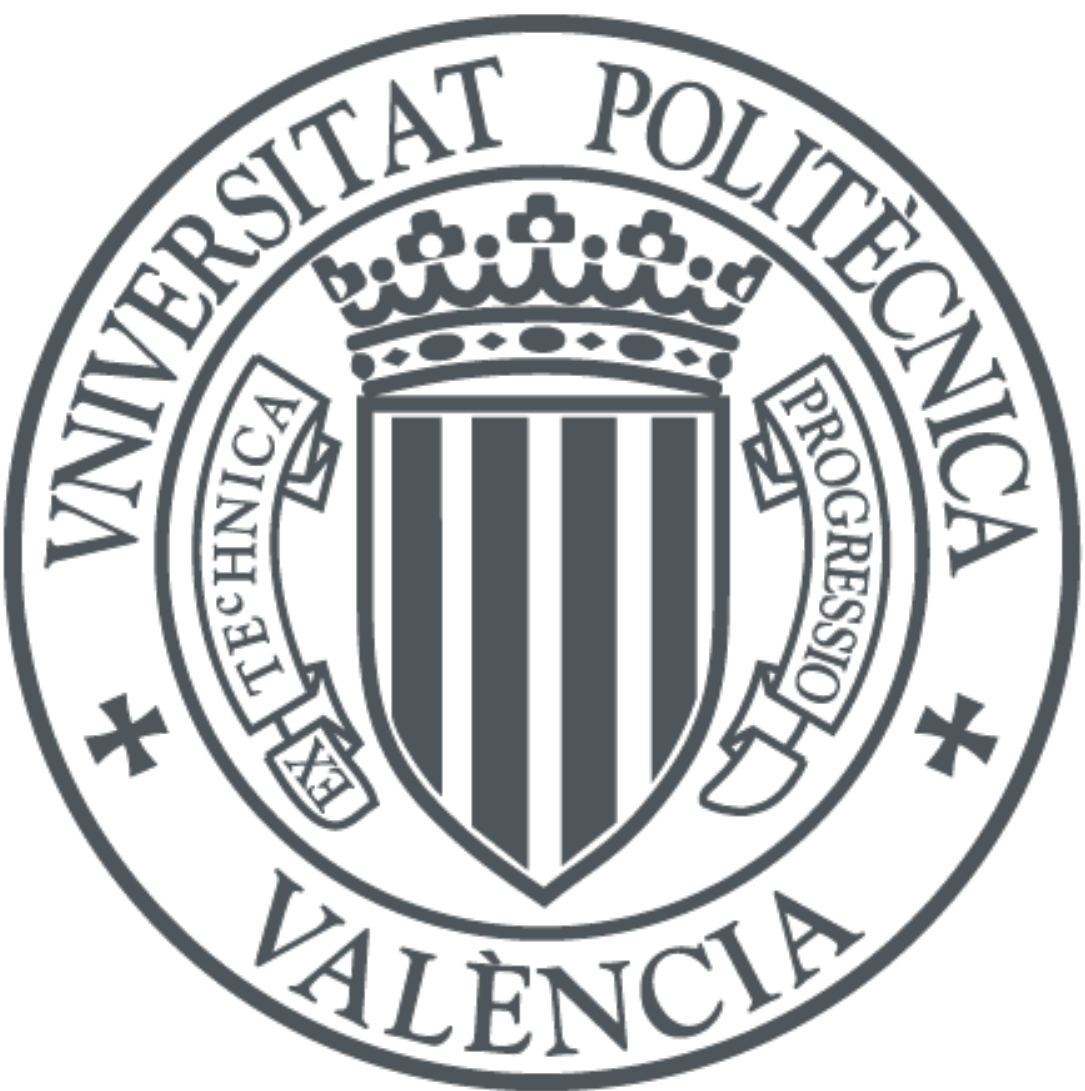

The final publication is available at

https://dx.doi.org/10.1111/jav.00589

Copyright Wiley; Oikos Editorial Office

Additional Information 


\section{Does fragmentation of wetlands affect gene flow in sympatric Acrocephalus warblers with different migration strategies?}

Francesco Ceresa, Eduardo J. Belda, Laura Kvist, Hamid Rguibi-Idrissi and Juan S. Monrós

F. Ceresa (francesco.ceresa01@gmail.com) and J. S. Monrós, Institute Cavanilles of Biodiversity and Evolutionary Biology, University of Valencia, C/Catedrático José Beltrán 2, ES-46980 Paterna (Valencia), Spain. - E. J. Belda, IGIC, Universidad Politécnica de Valencia, C/Paranimf 1, ES46730 Gandia (Valencia), Spain. - L. Kvist, Department of Biology, University of Oulu, PO Box 3000, FI-90014 Oulu, Finland. - H. Rguibi-Idrissi, équipe de recherche 'Valorisation des ressources naturelles et biodiversite', Faculté des Sciences, BP 20, MA-24000 El Jadida, Morocco. 


\section{Abstract}

3 Wetlands are naturally patchy habitats, but patchiness has been accentuated by the extensive

4 wetlands loss due to human activities. In such a fragmented habitat, dispersal ability is especially

5 important to maintain gene flow between populations. Here we studied population structure, genetic

6 diversity and demographic history of Iberian and North African populations of two wetland

7 passerines, the Eurasian reed warbler Acrocephalus scirpaceus and the moustached warbler

8 Acrocephalus melanopogon. These species are closely related and sympatric in our study sites, but

9 the reed warbler is a long-distance migrant and widespread bird while the moustached warbler is

10 resident or migrates over short distances, and breeds across a more discontinuous range. Using

11 microsatellites and mtDNA data, we found higher population differentiation in moustached than in

12 reed warbler, indicating higher dispersal capability of the latter species. Our results also suggest that

13 the sea limits dispersal in the moustached warbler. For both species, we found evidence of gene

14 flow between study sites, indicating the capability of compensating for habitat fragmentation.

15 However, in most cases gene flow was restricted, possibly because of the large distances between

16 study sites (from c. 290 to $960 \mathrm{~km}$ ) or breeding site fidelity. Haplotype diversity was higher for the

17 reed warbler, possibly because of a more important contribution of dispersal from different

18 populations and the higher population size. Studying demographic history, we obtained signs of

19 postglacial population growth for both species, and evidences of a recent colonization or re-

20 colonization of the Mallorca Island by the moustached warbler. 
23 Habitat fragmentation consists of reduction of the total habitat area and creation of separate patches

24 from a wider continuous distribution (Frankham et al. 2010). The consequences of habitat

25 fragmentation on the demographic and genetic structure of a natural population vary according to

26 both landscape features (degree of habitat isolation, type of matrix between fragments) and species

27 characteristics (population size and density, dispersal ability, stress tolerance; Matthysen et al. 1995,

28 Newton 1998, Bohonak 1999, Desrochers et al. 1999, Galbusera et al. 2004). Wetlands are patchy

29 habitats immersed in a terrestrial matrix, and this natural characteristic of discontinuity has been

30 accentuated by the extensive habitat destruction caused by human activities (Finlayson et al. 1992,

31 Van Vessem et al. 1997, Paracuellos and Telleria 2004, Silva et al. 2007, Laurence 2010). In such a

32 scattered habitat, the dispersal ability of a species is crucial to produce sufficient gene flow to

33 reduce the impact of population fragmentation. Lack of gene flow between fragmented populations

34 can lead to loss of genetic diversity (e.g. Kvist et al. 2011), inbreeding and consequently higher

35 extinction risk compared to a continuous population (Frankham et al. 2010). Dispersal ability of

36 birds is generally high (Koenig et al. 1996, Frankham et al. 2010), but detailed species-specific

37 estimates are difficult to obtain. This is largely due to practical difficulties; studying dispersal over

38 large distances requires large-scale marking schemes (Paradis et al. 1998, Hansson et al. 2002), and

39 the use of satellite telemetry or geolocators is usually possible only on a reduced number of

40 individuals due to the high costs. However, indirect genetic methods can provide useful information

41 about gene flow and population differentiation.

42 Here we present new information of genetic diversity and population structure of two

43 closely related and sympatric wetland passerines with different migration strategies, the moustached

44 warbler Acrocephalus melanopogon and the Eurasian reed warbler Acrocephalus scirpaceus

45 (hereafter reed warbler), based on both microsatellites and mitochondrial DNA data. 
The moustached warbler is a polytypic species breeding across a discontinuous area ranging

47 from SW Europe to Central Asia (Kennerley and Pearson 2010). Our study populations in Spain

48 belong to the nominal subspecies melanopogon, which occupy the western part of the species range.

49 These populations are mostly sedentary or migrate over short distances (Castany 2003, Castany and

50 López 2006, Kennerley and Pearson 2010). In Spain, the distribution of the moustached warbler is

51 discontinuous and most of the $\sim 1000$ breeding pairs are concentrated in a few marshlands along the

52 Mediterranean Coast and on the Mallorca Island (Castany and López 2006). Until now, no

53 information about genetic diversity and genetic population structure has been provided for this 54 species.

The reed warbler is a common and largely widespread breeding bird in Europe. This species 56 is a long-distance migrant wintering in sub-Saharan Africa (Kennerley and Pearson 2010); a 57 migratory divide in Central Europe splits the European reed warbler population (subspecies 58 scirpaceus) into SW- and SE-migrating populations (Procházka et al. 2008). Iberian reed warblers

59 belong to the SW-migrating group, have more rounded and shorter wings (Cramp 1992, Peiró 2003)

60 and winter more north than the other SW-migrating populations (Procházka et al. 2008). Procházka

61 et al. (2011), using ten microsatellite loci, found no clear population structure and low genetic 62 differentiation of reed warbler populations across Europe, indicating a high level of gene flow.

63 Furthermore, the authors reported slight, but significant, differentiation of Iberian populations and 64 suggested that they may have a different evolutionary history than other populations. North African reed warblers seem to be partly sedentary (Amezian et al. 2010, Kennerley and Pearson 2010) and birds breeding in Morocco differ from European reed warblers also in biometrics, coloration and moult strategy (Amezian et al. 2010, Jiguet et al. 2010). On this basis, some authors suggest that 68 these birds could constitute a new taxon (Amezian et al. 2010, Jiguet et al. 2010), thus the status of this population is still unclear. 
71 structure and population history of the study species in Iberia (and also in North Africa for the reed

72 warbler), 2) to assess the possible effects of habitat fragmentation on the genetic diversity and

73 structure of the study populations and 3) to compare the results obtained for the two species, taking

74 into account especially their differences in migration strategy and population size.

\section{Methods}

\section{Sampling and DNA extraction}

81 We obtained blood samples from birds mist-netted during the breeding season of 2012-2013 at four 82 study areas: the Pego-Oliva Natural Park (38 $\left.51^{\prime} \mathrm{N}-0^{\circ} 03^{\prime} \mathrm{W}\right)$, S'Albufera de Mallorca $\left(39^{\circ} 47^{\prime} \mathrm{N}\right.$ $\left.833^{\circ} 06^{\prime} \mathrm{E}\right)$ and Villafranca de los Caballeros $\left(39^{\circ} 27^{\prime} \mathrm{N}-3^{\circ} 19^{\prime} \mathrm{W}\right)$ in Spain and Larache $\left(35^{\circ} 08^{\prime} \mathrm{N}-\right.$ $846^{\circ} 05^{\prime} \mathrm{W}$ ) in Morocco (Fig. 1). At the last site, the breeding population of moustached warbler is 85 small and we captured no individuals. Blood drops $(5-15 \mu \mathrm{l})$ were obtained from the brachial vein 86 and stored in 96\% ethanol. Overall, we sampled 54 moustached warblers and 68 reed warblers. We

87 extracted DNA using UltraClean ${ }^{\mathrm{TM}}$ Blood $\operatorname{Spin}^{\mathrm{TM}}$ Kit (MoBio Laboratories) according to the 88 protocol.

90 DNA amplification

92 Microsatellites

93

94 We amplified 16 polymorphic microsatellite loci from reed warbler DNA samples: Ase25, Ase34, 95 Ase37, Ase48, Ase58 (Richardson et al. 2000, Acrocephalus sechellensis), Pocc2 (Bensch et al. 
1997, Phylloscopus occipitalis), Ppi2 (Martínez et al. 1999, Pica pica), Aar4, Aar5 (Hansson et al.

97 2000, Acrocephalus arundinaceus), FhU2 (Ellegren 1992, Ficedula hypoleuca), Pca3 (Dawson et

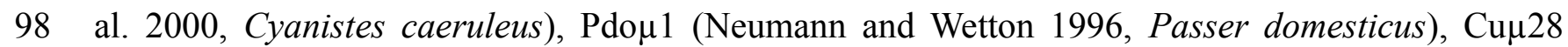

99 (Gibbs et al. 1999, Catharus ustulatus), Gf05 (Petren 1998, Geospiza fortis), Pdo5 (Griffith et al.

100 1999, P. domesticus) and ZL54 (Frentiu et al. 2003, Zosterops lateralis). In the case of the 101 moustached warbler, we successfully amplified eight polymorphic loci: Ase18 (Richardson et al. 102 2000, A. sechellensis), Aar4, Pdo5, Ppi2, ZL54, Pocc2, Pca3 and Ase25. Details on the Polymerase 103 Chain Reaction (PCR) are available in the online supplementary material. We ran the PCR products 104 with ABI PRISM 3730 DNA Analyzer (Applied Biosystems) and scored them with GeneMapper 105 4.0. We checked the data with the program MICROCHECKER 2.2.3 (van Oosterhout et al. 2004) 106 for possible genotyping errors (null alleles, scoring errors due to stuttering, large allele dropouts).

108 Mitochondrial DNA

110 For reed warblers we amplified $473 \mathrm{bp}$ of the mitochondrial cytochrome oxidase CO1 using primers $111 \mathrm{CO1F}$ and CO1R (Hebert et al. 2004). For moustached warblers we amplified 623 bp of the CO1 112 using primers CO1F and CO1R2 (Kerr et al. 2007). Details on the PCR procedures are available in 113 the online supplementary material. For reed warblers, we sequenced both strands, while for 114 moustached warblers we sequenced all individuals with forward and 26 individuals also with 115 reverse primers. We used the BigDye ${ }^{\mathrm{TM}}$ Terminator 3.1 Cycle Sequencing Kit (Applied Biosystems) 116 and ran the sequencing reactions with ABI PRISM 3730 automatic sequencer (Applied 117 Biosystems). We obtained sequences of 50 reed warblers and 43 moustached warblers and we 118 checked and aligned them with BioEdit 7.2.5 (Hall 1999).

\section{Statistical analysis}


122 Microsatellites

124 We tested the possible deviations from the Hardy-Weinberg and linkage equilibrium with

125 GENEPOP 4.2 (Raymond and Rousset 1995, Rousset 2008), for each sampling site and for the total 126 sample of both species. For the same groups we calculated the expected heterozygosity $\left(\mathrm{H}_{\mathrm{e}}\right)$ with 127 Arlequin 3.5.1 (Excoffier et al. 2010) and inbreeding coefficient $\left(\mathrm{F}_{\text {IS }}\right)$ and allelic richness (A) with 128 FSTAT 2.9.3 (Goudet 1995).

To infer the population genetic structure we used the program STRUCTURE 2.3.4

130 (Pritchard et al. 2000, Falush et al. 2003). This program is based on a Bayesian approach and allows 131 estimation of the most probable number of distinct genetic clusters $(\mathrm{K})$ in the data set. We chose a 132 model with population admixture and correlated allele frequencies (Falush et al. 2003), and 133 performed the analysis without any prior spatial information. We performed ten independent runs 134 for each value of $\mathrm{K}$ between 1 and 10, with a burn-in period of 50000 iterations and 500000 Markov chain Monte Carlo (MCMC) replications. Furthermore, we calculated the ad hoc statistic $\Delta \mathrm{K}$ from 136 the STRUCTURE results as described by Evanno et al. (2005), to better assess the real number of 137 genetic clusters. We investigated population differentiation also by calculating pairwise $\mathrm{F}_{\text {ST }}$ values 138 between each of the sampling sites using the program Arlequin.

We explored the spatial genetic structure with the program SPAGeDi 1.4 (Hardy and 140 Vekemans 2002), using the Loiselle kinship coefficient (Loiselle et al. 1995) and four (reed 141 warbler)/three (moustached warbler) distance classes. The spatial coordinates of the individuals 142 corresponded to the coordinates of the four sampling sites, and we built distance classes to include 143 one site per class. To obtain information about current dispersal between populations, we carried out 144 an assignment analysis and looked for first generation migrants with the program GENECLASS 2 145 (Piry et al. 2004). We used the Bayesian individual assignment methods by Rannala and Mountain 
146 (1997) and the simulation algorithm of Paetaku et al. (2004). For both assignment analysis and first

147 generation migrant detection, we used 1000 replicates, alpha level for the MCMC simulations at $148 \quad 0.01$ and assignment threshold at 0.05 .

149 Genetic data from population samples carry also information about population history. First,

150 we looked for past bottlenecks by means of the program BOTTLENECK 1.2.02 (Cornuet et al. 151 1996, Piry et al. 1999), which tests for heterozygosity excess caused by recent reduction of the 152 effective population size (Piry et al. 1999). We used the Wilcoxon test under the two-phase mutation 153 model with 95\% single-step mutations. We also estimated the Garza-Williamson index (Garza and 154 Williamson 2001) with Arlequin, in order to search for strong past population bottlenecks. Using 155 the genetic clusters identified by STRUCTURE, we studied the population history with the program 156 DIY ABC 2.0.3 (Cornuet et al. 2008), based on approximate Bayesian computation (ABC). Using 157 DIY $\mathrm{ABC}$ it is possible to compare different competing historical/demographic scenarios and to 158 obtain parameter estimators for each of them. For reed warblers, we found no population 159 differentiation with STRUCTURE ( $\mathrm{K}=1$, see Results), thus we performed the analysis in DIY $160 \mathrm{ABC}$ only for moustached warbler ( $\mathrm{K}=2$, see Results). We were interested to estimate the 161 divergence time and the current effective population sizes for the two STRUCTURE populations 162 (Spanish mainland and Mallorca Island, see Results) and for the ancestral population. We explored 163 five scenarios, the simplest one containing one divergence event while the remaining four contained 164 population size changes at different times after divergence in only one or both populations. We 165 chose the default range of priors for effective population sizes and divergence times (10-10000) and 166 set the conditions for the chronological order of historical events. We adopted the default 167 Generalized Stepwise Mutation model (Estoup et al. 2002) and seven of 11 default summary 168 statistics (four within- and three among-populations). With these settings, a total of 5000000 169 simulated data sets were calculated (1000000 per scenario); among them, the 50000 sets closest to 170 the observed data according to the summary statistics were used for parameter estimation. 
174 We calculated haplotype and nucleotide diversities of the entire sample and of each population for 175 both species using DnaSP 5.10.01 (Librado and Rozas 2009). To build a statistical parsimony 176 network, we used the program TCS 1.21 (Clement et al. 2000) with default settings of 95\% 177 parsimony connection limit. As outgroups, we included sequences from other European populations 178 obtained from the GenBank (accession numbers and origin: moustached warbler - GQ481257, 179 Russia; reed warbler - GU571698, Sweden).

We used the program Arlequin to obtain information about population differentiation, by 181 performing an analysis of molecular variance (AMOVA) and calculating pairwise $\phi_{\mathrm{ST}}$ values 182 between each of the sampling sites using pairwise differences and frequencies of haplotypes.

We studied demographic history by means of mismatch distribution analysis, which consists

184 of computing the distribution of the observed number of differences between pairs of sequences in a 185 sample. Unimodal distributions usually indicate an expansion event, whereas multimodal 186 distributions are typical of populations at demographic equilibrium (Rogers and Harpending 1992). 187 In addition, we carried out Tajima's D (Tajima 1989) and Fu's Fs (Fu 1997) neutrality tests, where a statistically significant negative value indicates a recent expansion event. We performed mismatch distribution analysis and the neutrality tests for the entire sample and for each sampling site using Arlequin and DnaSP.

The reed warbler mismatch distribution suggested an admixture of two previously isolated 192 populations (see Results). Thus, we ran reed warbler data with DIY ABC to estimate the timing of 193 this demographic event. We compared four scenarios, where the simplest one consisted of a 194 population admixture at time $t_{a}$ and a previous population divergence at time $t_{2}$. The remaining three 195 scenarios followed the same basic setting but included population size changes at different times for 
196 only one or both populations before admixture. Reed warbler populations in Iberia and across

197 Europe are abundant (Carrascal and Palomino 2008, BirdLife International 2014), thus we set the 198 maximum effective population size at 1000000 individuals in the model. As maximum time for the 199 admixture and the previous divergence events we chose 10000 and 20000 generations 200 (corresponding to 10000 and 20000 years for the study species), respectively. We used the Kimura 201 two parameters mutation model (Kimura 1980) and all default summary statistics. A total of 2024000000 simulated data sets were calculated (1000000 per scenario); among them, the 40000 sets 203 closest to the observed data according to the summary statistics were used for parameter estimation.

206 Results

\section{Reed warbler}

210 Microsatellites

212 Using MICROCHECKER we found possible null alleles in loci Ase25, Ase37, Ase48 and ZL54.

213 We excluded these loci from calculations for the Hardy-Weinberg equilibrium, linkage 214 disequilibrium and inbreeding coefficient, as well as from BOTTLENECK analysis, while for the 215 other analyses we used all 16 loci. We found no evidences of large allele dropouts or scoring errors 216 in the data set.

217 We found no significant deviations from Hardy-Weinberg equilibrium for any sampling site 218 or for the entire data set. Linkage disequilibrium was found only for FhU2 and Pca3 in the 219 Villafranca population and in the entire sample. Basic polymorphism parameters (Table 1) showed 220 similar values across the four sampling sites, ranging from the highest polymorphism in Villafranca 
$221\left(\mathrm{H}_{\mathrm{e}}=0.710, \mathrm{~A}=1.71\right)$ to the lowest in Mallorca $\left(\mathrm{H}_{\mathrm{e}}=0.650, \mathrm{~A}=1.65\right)$.

The program STRUCTURE attributed the highest likelihood $(-2412)$ to $\mathrm{K}=1$, although $\mathrm{K}=$

2232 obtained a similar support $(-2417) . \Delta \mathrm{K}$ showed a peak at $\mathrm{K}=2$, but as it is not possible to

224 compute $\Delta \mathrm{K}$ for $\mathrm{K}=1$, we could not compare the two hypotheses based on this statistic. The

225 STRUCTURE bar plot obtained for $\mathrm{K}=2$ (Fig. 2) support the $\mathrm{K}=1$ hypothesis, because all

226 individuals showed approximately equal probability of belonging to both of the two clusters. To

227 detect a possible weak population structuring we repeated the analysis adding geographical

228 information (LOCPRIOR model), but we obtained similar results. Therefore, the most supported

229 hypothesis is the lack of a clear population structuring in the sample. Nonetheless, in two cases

230 (Larache - Pego-Oliva and Villafranca - Mallorca) pairwise $\mathrm{F}_{\mathrm{ST}}$ values between sampling sites were

231 significant, though low (Table 2).

232 Using the program SPAGeDi, the regression between the kinship coefficients of individual

233 pairs and the logarithm of the distances between sampling sites was significantly negative $(\mathrm{r}=$

$234-0.058, \mathrm{p}=0.042)$. However, given the low regression coefficient, this result does not represent a

235 clear evidence for isolation by distance. Out of 68 birds, 25 (38\%) were not assigned to their

236 sampling sites (Table 3) by the assignment test. Two birds sampled at Mallorca were identified as

237 first generation migrants and assigned to Pego-Oliva. Both individuals (a male with evident cloacal

238 protuberance and a female with brood patch) were breeding when sampled, thus this result indicates

239 possible evidence of dispersal.

240 We found no evidence of past bottlenecks according to the shapes of allele frequency

241 distributions or excess of heterozygotes for the entire data set and for Larache and Villafranca

242 samples (Table 1). Pego-Oliva and Mallorca samples were too small to perform the analysis. The

243 Garza-Williamson (G-W) index provides a sign of past bottleneck when is lower than 0.68 while

244 excludes this event if exceeds 0.8 (Garza and Williamson 2001). Based on this, the entire and the

245 Larache samples did not show evidence of past bottlenecks, in Villafranca the G-W index was 
246 intermediate and Pego-Oliva and Mallorca values were lower than 0.68 (Table 1). However, the

247 results of the latter two sites are poorly reliable due to the low sample size. Overall, we found no 248 clear evidence of past bottlenecks.

\section{Mitochondrial DNA}

252 The 50 sequenced reed warblers belonged to 18 different haplotypes. The TCS cladogram (Fig. 3) 253 show a star-like structure, with one dominant haplotype including 25 individuals (50\% of the total) 254 and 17 other haplotypes represented by few birds (1-4). This structure suggests past population expansion events. Four birds resulted to be more related to the outgroup individual from Sweden than to the remaining Iberian/African sample (Fig. 3). Haplotype and nucleotide diversities are reported in Table 4.

AMOVA analysis did not detect any population differentiation $\left(\phi_{\mathrm{ST}}=-0.0087, \mathrm{p}=0.438\right)$, pairwise $\phi_{\text {ST }}$ values between study sites (Table 5).

According to the neutrality tests, we found signs of population expansion for Larache and, less clearly, for the entire data set. In fact, Tajima's D and Fu's Fs were significantly negative for Larache sample $(\mathrm{D}=-2.203, \mathrm{p}<0.01 ; \mathrm{Fs}=-7.063, \mathrm{p}=0.001)$, not significant for Pego-Oliva and

264 Villafranca, while over the whole sample only Fu's Fs was significantly negative $(D=-1.581, p>$ 0.05; Fs $=-8.590, \mathrm{p}<0.001)$. Mismatch distribution did not detect significant deviations from the expansion hypothesis. Furthermore, mismatch distribution of Larache, Villafranca and the whole data set showed a bimodal shape (Fig. 4), suggesting a past admixture of previously isolated populations. Exploring demographic history with DIY ABC, the scenario with populations size change in one population before admixture (hereafter A; Fig. 5) resulted to be the best. However, the simplest scenario with an admixture and a previous divergence event, without population size 
271 changes (hereafter B; Fig. 5), obtained high support too, thus we report the parameters estimates 272 obtained from both scenarios (Fig. 5). Scenario A obtained lower posterior probability than B 273 according to direct estimation $(\mathrm{A}=0.386, \mathrm{~B}=0.440)$, but the logistic approach clearly supported 274 scenario $\mathrm{A}(\mathrm{A}=0.841, \mathrm{~B}=0.159)$. Thus, we performed the analysis of confidence in scenario 275 choice over all scenarios as implemented in DIY ABC, which confirmed scenario A as the best but 276 with high Type I error (56.8\% according to direct approach, 55.4\% to logistic approach) due to the 277 good performance of scenario B. Both scenarios fitted the data well according to model checking, 278 with no significant deviation in summary statistics between posterior distributions and observed 279 data. Timing of admixture was estimated to be 5690 generations ago (CI 95\% 583 - 9610) from 280 scenario A and 4750 generations (CI 95\% 505 - 9420) from scenario B. In both species, the first 281 breeding occurs at the age of 1 year (like in most passerines, Noon and Sauer 1992), thus we 282 assumed that this time corresponded to one generation.

284 Moustached warbler

286 Microsatellites

288 MICROCHECKER detected possible null alleles in loci Ase18 and Ase25, thus we excluded them 289 from the same analyses as listed for the reed warbler. For the remaining analyses, we used all eight 290 loci. We found no evidence of large allele dropouts or scoring errors in the data set.

The whole sample was not in Hardy-Weinberg equilibrium $\left(\chi_{32}^{2}=\infty, p=\right.$ highly significant $)$, 292 nor was Pego-Oliva $\left(\chi_{12}^{2}=\infty, \mathrm{p}=\right.$ highly significant $)$ and Mallorca samples $\left(\chi_{12}^{2}=47.18, \mathrm{p}<\right.$ 293 0.001), while for Villafranca the test was not significant $\left(\chi_{12}^{2}=20.01, p=0.067\right)$. We found no 294 significant linkage disequilibrium between loci. We obtained higher expected heterozygosity $\mathrm{H}_{\mathrm{e}}$ and 295 allelic richness A values and lower inbreeding coefficients $\mathrm{F}_{\mathrm{IS}}$ for the mainland sites of Pego-Oliva 
and Villafranca than for the Mallorca sample (Table 1).

Using the program STRUCTURE, we obtained the highest support in terms of likelihood for $\mathrm{K}=3(-919)$. However, at $\mathrm{K}=2$ (likelihood $=-935)$ we observed a clear peak of $\Delta \mathrm{K}$, indicating that the most reliable structuring is the occurrence of two clusters. In the STRUCTURE bar plot (Fig. 2) the Mallorca sample is clearly distinct from the remaining individuals, thus we identified two clusters corresponding to Mallorca and the Spanish mainland (Pego-Oliva + Villafranca sampling sites). Pairwise $\mathrm{F}_{\mathrm{ST}}$ values were significant between all sampling sites, as well as between the STRUCTURE populations (Table 2).

We did not find any correlation between the Loiselle kinship coefficients and logarithms of distances $(\mathrm{r}=0.000, \mathrm{p}=0.825)$ when studying isolation by distance with the program SPAGeDi. The assignment analysis did not assign 12 out of 54 (22\%) individuals to their sampling sites (Table 3). Considering the STRUCTURE populations, 6 out of 54 birds (11\%) were not assigned to their cluster (Table 3). One bird sampled in Mallorca and one in Villafranca were identified as first generation migrants and assigned to Pego-Oliva. The first was a female with regressing brood patch and the second a male with evident cloacal protuberance (i.e. breeding individuals), thus our results suggest dispersal between the study sites.

We found signs of recent population reduction in Mallorca with the program BOTTLENECK (Wilcoxon test, heterozygosity excess, $\mathrm{p}=0.023$; shifted allele frequency class mode) and less clearly for the Spanish mainland STRUCTURE population (Wilcoxon test, heterozygosity excess, $p=0.039$; normal L-shape of allele frequency distribution). No evidence of past bottlenecks was found for Pego-Oliva and Villafranca samples. G-W indexes were always > 0.8 , indicating no bottleneck history in a more remote past. We obtained further information about demographic history using the program DIY ABC. Out of the five simulated scenarios, the best was the simplest one (Fig. 6), with divergence at time $t_{1}$ and no effective population size $\left(\mathrm{N}_{\mathrm{e}}\right)$ change after divergence. Posterior probabilities of this scenario were 0.970 according to direct estimation 
321 and 0.991 according to logistic approach. The model checking based on seven summary statistics

322 and the PCA analysis supported the reliability of the scenario, with the exception of two summary

323 statistics (mean M index, Garza and Williamson 2001; $(\delta \mu)^{2}$ distance, Goldstein et al. 1995) where

324 posterior distributions strongly deviated $(0.01>p>0.001)$ from the observed data. The estimate of

325 divergence time was 230 generations (95\% CI $41-449)$, corresponding to 230 years. $\mathrm{N}_{\mathrm{e}}$ estimate

326 for Spanish mainland was 4460 (95\% CI 1240 - 6360), and 1500 for Mallorca (95\% CI 290 - 2740).

327 The ancient population size (before divergence) was estimated to be 5890 (95\% CI 1430 - 7820).

329 Mitochondrial DNA

331 The 43 sequenced moustached warblers belonged to seven different haplotypes. Similarly to the 332 reed warbler, TCS cladogram (Fig. 3) showed a star-like structure, suggesting past population 333 expansion. A dominant haplotype included 35 individuals ( $81 \%$ of the total), while the other six 334 haplotypes were represented by one or two birds. Compared to the reed warbler, haplotype and 335 nucleotide diversity (Table 4) are markedly lower.

336 We did not find significant differentiation between sampling sites with AMOVA analysis $337\left(\phi_{\mathrm{ST}}=0.0363, \mathrm{p}=0.108\right)$, while using the populations identified by STRUCTURE, we obtained a 338 significant result $\left(\phi_{\mathrm{ST}}=0.0862, \mathrm{p}=0.022\right)$, with $8.62 \%$ variation due to differences among 339 populations and $91.38 \%$ within populations. Pairwise $\phi_{\mathrm{ST}}$ values were significant between 340 STRUCTURE populations and between Pego-Oliva and Mallorca samples, and not significant 341 between the other sampling sites (Table 5).

342 The results of neutrality tests suggested past expansion for the whole sample $(\mathrm{D}=-1.954, \mathrm{p}$ $343<0.05 ; \mathrm{Fs}=-5.308, \mathrm{p}=0.004)$, but not for the single sampling sites or for the STRUCTURE 344 populations. Mismatch distribution did not detect significant deviations from the expansion 345 hypothesis. 
348 Discussion

350 Reed warbler

352 Our results indicate high gene flow between the sampling sites, suggesting high dispersal capability

353 for the reed warblers. However, a weak but significant differentiation among some of the sampling 354 sites (Table 2) indicates that gene flow is partly restricted. Other researchers obtained similar results 355 studying the reed warbler across the whole Europe (Procházka et al. 2001) and in Croatia (Kralj et 356 al. 2010). A possible cause of gene flow restriction in our study is the relatively large distance 357 between sampling sites (from c. 290 to $960 \mathrm{~km}$ ), but testing for isolation by distance did not clearly 358 support this hypothesis. Breeding site fidelity, reported for this species especially for adult birds 359 (Vadász et al. 2008), could also explain limitations to gene flow. Given the lack of a clear 360 structuring in a sample including birds breeding in Spain (subspecies scirpaceus) and in Morocco, 361 our results do not support the hypotheses that the latter belong to a new taxon (see Introduction; 362 Amezian et al. 2010, Jiguet et al. 2010). Besides the geographical proximity of the two areas, 363 Morocco is crossed by the migration routes of the European SW-migrating populations, which 364 includes the Iberian reed warblers (Procházka et al. 2008), and this is likely to facilitate the 365 exchange of individuals between Moroccan and Iberian populations.

366 Our results about demographic history indicate past population growth and mixing of 367 previously isolated populations. The dating of this population admixture calculated in DIY ABC 368 (Fig. 5) is compatible with a postglacial expansion from a refugium area. In fact, during and before 369 this time the climate became warmer and wetter, causing the expansion of the suitable habitat also 370 for many other species (Murray Gates 1993, Wright et al. 1993, Hewitt 2000, Dubey et al. 2006). 
371 Arbabi et al. (2014) investigated phylogeography of reed warblers with mtDNA data and identified

372 three evolutionary lineages corresponding to three subspecies (scirpaceus, fuscus and avicenniae),

373 which had remained isolated in three different glacial refugia during the Middle Pleistocene

374 glaciations. Procházka et al. (2011) suggested that it is possible that the Iberian Peninsula was one

375 of the refugium areas for reed warblers, as has been documented for many other species (Hewitt

376 2004). As we did, also Arbabi et al. (2014) found evidence of population growth, but their samples

377 were mainly from Germany, representing the subspecies scirpaceus. Comparing diversity indices,

378 both haplotype and nucleotide diversities were higher in our study $(\mathrm{N}=50 ; \mathrm{h}=0.745 ; \pi=0.006)$

379 than in Germany $(\mathrm{N}=347 ; \mathrm{h}=0.544 ; \pi=0.002)$ or for the whole sample of subspecies scirpaceus

$380(\mathrm{~N}=380 ; \mathrm{h}=0.558 ; \pi=0.002)$ in Arbabi et al. (2014). The higher diversity in our study area can be

381 a sign of more ancient refugium area (Taberlet et al. 1998, Comes and Kadereit 1998) than

382 suggested by Arbabi et al. (2014), or, more likely, a result of the relatively recent admixture event.

383 The population divergence preceding the admixture, according to both DIY ABC scenarios (Fig. 5),

384 is posterior to the Last Glacial Maximum and could have been caused by the colonization of

385 separated areas by individuals originating from the same glacial refugium. Due to the drier climate,

386 wetland areas were probably scarcer than currently, thus making it plausible that habitats suitable

387 for reed warblers were sparse and isolated enough to promote population divergence.

389 Moustached warbler

391 The results obtained from microsatellite data indicate that gene flow is limited between the Spanish

392 mainland and Mallorca Island (also according to the mtDNA results, see Table 5) and partly

393 restricted among the two mainland sites. Approximately the same distance (c. $290 \mathrm{~km}$ ) separates

394 Pego-Oliva from Villafranca and from Mallorca, but only the Mallorcan sample was clearly distinct

395 according to STRUCTURE analysis. This fact suggests that gene flow between the Spanish 
mainland and Mallorca is likely to be limited not only by the distance, but also by the sea (c. 200

$397 \mathrm{~km}$ wide) between the coast and the island. Thus, our results suggest that the sea forms an effective

398 dispersal barrier and limits gene flow in moustached warblers, at least for our study populations.

399 For a warbler, crossing the sea implies the lack of resting and foraging opportunities until reaching

400 land, resulting to more risky and difficult displacement than over the solid ground. The

401 GENECLASS results suggest that limited dispersal from the mainland to Mallorca can occur.

402 However, it is possible that the classification of a breeding bird as a first generation migrant is not

403 due to a real dispersal event, but to false detection due to small sample size or due to the sampling

404 sites not being in H-W equilibrium (Excoffier and Heckel 2006). The low differentiation among the

405 mainland sites indicates the occurrence of gene flow between the important breeding populations of

406 the Mediterranean coast and the small and scattered inland populations breeding in Castilla-La

407 Mancha (estimated to be only 10 pairs by Castany and López 2006), represented respectively by

408 Pego-Oliva and Villafranca samples in our study. The breeding bird sampled in Villafranca and

409 classified as first generation migrant from Pego-Oliva can be a further sign of dispersal. The gene

410 flow, however, is partly restricted, possibly because the two populations are divided by a wide area

411 without any other known breeding populations (Castany and López 2006) and without suitable

412 habitat. Like for reed warblers, breeding site fidelity in moustached warblers (Vadász et al. 2008)

413 could also reduce dispersal.

mtDNA showed evidence of past population growth, probably a sign of postglacial

415 expansion. As for reed warblers, it is likely that moustached warbler populations were confined in

416 glacial refugia and extended their range across Europe as the climate became warmer and wetter.

417 Taking into account the population structuring and the results of BOTTLENECK and coalescence

418 analysis, we conclude that Mallorca has been recently colonized or re-colonized by individuals

419 originating from the mainland. After the settlement of the breeding population, the limited gene

420 flow produced the population structuring we observed. 
422 Differences in population structure and demographic history between the two species -

\section{3 possible explanations}

425 The lower genetic differentiation found in reed warblers indicates a higher dispersal ability in them

426 than in moustached warblers. This is consistent with Paradis et al. (1998), who found long-distance

427 migrants to have higher dispersal ability than sedentary or short-distance migrants. Also other

428 researchers have reported lower intraspecific differentiation in migratory than in sedentary bird

429 species (e.g. Gill et al. 1993, Lovette et al. 1998, Arguedas and Parker 2000). Our results suggest

430 that differences in dispersal ability between reed and moustached warblers also can result from

431 different capability in crossing natural barriers, in this case stretches of sea. Migration routes of reed

432 warblers include crossing the Mediterranean Sea, thus crossing this kind of a barrier is a necessary

433 ability for this species. Conversely, migration of Spanish and French populations of moustached

434 warblers mostly follow the Mediterranean coast (Castany 2003) and do not necessarily require

435 crossing the sea, thus overcoming such a barrier is probably less common for these birds. Higher

436 differentiation in moustached warblers could be also due to the smaller population size and the

437 more discontinuous breeding range than in reed warblers. In fact, breeding areas of moustached

438 warblers are more isolated from each other, making the exchange of individuals more difficult. In

439 addition, Vadász et al. (2008), studying several warbler species in Hungary, reported higher

440 breeding site fidelity in moustached than in reed warblers. The authors hypothesized that the more

441 specialized habitat preferences of moustached warblers limit the opportunities of finding new

442 suitable areas, and that would result in reduced dispersal rates (Vadász et al. 2008). Similar studies

443 of the West Mediterranean moustached and reed warbler populations would be needed to assess if

444 breeding site fidelity is higher for moustached warblers also in this area. Differences in wing

445 morphology could also partly explain the difference in dispersal capability between the two species. 
446 In fact, reed warblers have more pointed wings than moustached warblers (Kennerley and Pearson

447 2010) allowing greater flight efficiency (e.g. Norbert 1989).

448 Both species showed signs of postglacial expansions, consistently with the findings of other

449 researchers studying European populations of wetland passerines (e. g. Hansson et al. 2008, Neto et

450 al. 2012, Arbabi et al. 2014). Haplotype diversity was higher for reed warblers, possibly because of

451 a more important contribution of dispersal from different populations and the higher population

452 size. Unlike in reed warblers, we did not find evidences of past population admixtures in

453 moustached warblers, indicating that the postglacial expansion of these species evolved in different

454 ways.

\section{Conclusion}

458 Despite the large distances between our sampling sites, we detected gene flow between sampling 459 sites for both reed and moustached warblers, although partly restricted or even limited in the case of 460 moustached warblers of Mallorca. These results suggest that both species are able to avoid the risk 461 of isolation derived from breeding in a fragmented habitat. We found lower differentiation in reed 462 warblers than in moustached warblers, indicating higher dispersal capability of reed warblers, a 463 species migrating over longer distances, with higher population size and more continuous breeding 464 range than moustached warblers. We did not find support for the occurrence of a new taxon of reed 465 warbler breeding in Morocco. Additional information from other breeding areas is needed for 466 moustached warblers in order to investigate population structuring and demographic history on a 467 larger scale. For both species, further information about dispersal is needed from large-scale 468 marking schemes. 
471 Acknowledgements - We acknowledge M. Rebassa, M. Marín, J. Gómez, Santi, Luis, Kames and

472 family and many others, who have helped us with the field work. We would also like to thank the

473 authorities of the Marjal de Pego-Oliva Natural Park, the S'Albufera de Mallorca Natural Park,

474 "Consejería de medio Ambiente y Desarrollo Rural de Castilla-La Mancha", the "Servei de

475 Conservació de la Biodiversitat de la Generalitat Valenciana" and the "Haut Commissariat aux Eaux

476 et Forêts et à la lutte contre la désertification de Rabat, Morocco" for providing the facilities to

477 work in protected areas and for the relevant permits. The people in these areas were always kind 478 and have greatly helped us in sampling reed and moustached warblers. We are grateful to M. Serra 479 and the researchers and Ph.D. students of the Laboratory of Evolutionary Ecology (Institute 480 Cavanilles of Biodiversity and Evolutionary Biology - University of Valencia), for providing the 481 laboratory and useful advices for DNA extraction. This study has been funded by Projects 482 CGL2005-02041/BOS and CGL2010-21933-C02-02 of the Spanish Ministry of Science and 483 Innovation. F. Ceresa was supported by an "Atraent talent" grant from the University of Valencia. 


\section{References}

498 Amezian, M., Cortes, J., Thompson, I., Bensusan, K., Perez, C., Louah, A., El Agbani, M. A. and 499 Qninba, A. 2010. Complete moult of an undescribed resident taxon of the Reed Warbler 500 Acrocephalus scirpaceus / baeticatus complex in the Smir marshes, Northern Morocco. - Ardea 98: $501 \quad 225-234$.

502

503 Arbabi, T., Gonzalez, J., Witt, H.-H., Klein, R. and Wink, M. 2014. Mitochondrial phylogeography 504 of the Eurasian Reed Warbler Acrocephalus scirpaceus and the first genetic record of A. s. fuscus in 505 Central Europe. - Ibis doi: 10.111/1ibi.12174

Arguedas, N. and Parker, P. G. 2000. Seasonal migration and genetic population structure in house wrens. - Condor 102: 517-528.

510 Bensch, S., Price, T. and Kohn, J. 1997. Isolation and characterization of microsatellite loci in a 511 Phylloscopus warbler. - Mol. Ecol. 6: 91-92.

513 BirdLife International. 2012. Acrocephalus scirpaceus. In: IUCN 2013. IUCN Red List of 514 Threatened Species. Version 2013.2. < www.iucnredlist.org >. Accessed on 06 June 2014.

516 Bohonak, A. J. 1999. Dispersal, gene flow, and population structure. - Q. Rev. Biol. 74: 21-45.

518 Carrascal, L. M. and Palomino, D. 2008. Las aves comunes reproductoras en España. Población en 519 2004-2006. - SEO/BirdLife. 
521 Castany, J. 2003. El carricerín real (Acrocephalus melanopogon) en el P. N. del Prat de Cabanes522 Torreblanca. Doctoral thesis. - University of Valencia.

524 Castany, J. and López, G. 2006. El carricerín real en España. I Censo Nacional (2005). 525 SEO/BirdLife.

527 Clement, M., Posada, D. and Crandall, K. A. 2000. TCS: a computer program to estimate gene 528 genealogies. - Mol. Ecol. 9: 1657-1660.

530 Comes, H. P. and Kadereit, J. W. 1998. The effect of Quaternary climatic changes on plant 531 distribution and evolution. - Trends Plant Sci. 3: 432-438.

533 Cornuet, J. M. and Luikart, G. 1996. Description and power analysis of two tests for detecting 534 recent population bottlenecks from allele frequency data. - Genetics 144: 2001-2014.

536 Cornuet, J. M., Santos, F., Beaumont, M. A., Robert, C. P., Marin, J. M., Balding, D. J., Guillemaud, 537 T. and Estoup, A. 2008. Inferring population history with DIY ABC: a user-friendly approach to 538 approximate Bayesian computation. Bioinformatics 24: 2713-2719.

540 Cramp, J. S. 1992. The Birds of the Western Palearctic. Vol. 6. - Oxford University Press.

542 Dawson, D. A., Hanotte, O., Greig, C., Stewart, I. R. K. and Burke, T. 2000. Polymorphic 543 microsatellites in the blue tit Parus caeruleus and their cross-species utility in 20 songbird families. 544 - Mol. Ecol. 9: 1941-1944. 
546 Desrochers, A., Hannon, S. J., Bélisle, M. and St. Clair, C. C. 1999. Movement of songbirds in

547 fragmented forests: can we scale-up from behaviour to explain occupancy patterns in the landscape?

548 In: Proceedings of the $22^{\text {nd }}$ International Ornithological Congress Johannesbourg (eds Adams, N. J.

549 and Slotow, R. H.), pp. 2447-2464. - BirdLife South Africa.

550

551 Dubey, S., Zaitsev, M., Cosson, J., Abdukadier, A. and Vogel, P. 2006. Pliocene and Pleistocene 552 diversification and multiple refugia in a Eurasian shrew (Crocidura suaveolens group). - Mol.

553 Phylogenet. Evol. 38: 635-647.

555 Ellegren, H. 1992. Polymerase-chain-reaction (PCR) analysis of microsatellites - a new approach to 556 studies of genetic relationships in birds. - Auk 109: 886-895.

558 Estoup, A., Jarne, P. and Cornuet, J. M. 2002. Homoplasy and mutation model at microsatellite loci 559 and their consequences for population genetics analysis. - Mol. Ecol. 11: 1591-1604.

561 Evanno, G., Regnaut, S. and Goudet, J. 2005. Detecting the number of clusters of individuals using 562 the software STRUCTURE: a simulation study. - Mol. Ecol. 14: 2611-2620.

564 Excoffier, L. and Heckel, G. 2006. Computer programs for population genetics data analysis: a 565 survival guide. Nature Reviews Genetics 7: 745-758.

567 Excoffier, L. and Lischer, H. 2010. Arlequin suite ver 3.5: a new series of programs to perform 568 population genetics analyses under Linux and Windows. - Mol. Ecol. Resour. 10: 564-567.

570 Falush, D., Stephens, M. and Pritchard J. K. 2003. Inference of population structure using 
multilocus genotype data: linked loci and correlated allele frequencies. - Genetics 164: 1567-1587.

573 Finlayson, M., Hollis, T. and Davis, T. 1992. Managing Mediterranean Wetlands and their Birds.

574 The International Waterfowl and Wetlands Research Bureau Spec. Publ. No. 20. - The International

575 Waterfowl and Wetlands Research Bureau.

577 Frankham, R., Ballou, J. D. and Briscoe, D. A. 2010. Introduction to Conservation Genetics, second 578 ed. - Cambridge University Press.

580 Frentiu, F. D., Lange, C. L., Burke, T. and Owens, I. P. F. 2003. Isolation of microsatellite loci in the 581 Capricorn silvereye, Zosterops lateralis chlorocephalus (Aves: Zosteropidae). - Mol. Ecol. Not. 3: $582 \quad 462-464$.

$584 \mathrm{Fu}, \mathrm{Y} . \mathrm{X}$. 1997. Statistical tests of neutrality of mutations against population growth, hitchhiking 585 and background selection. - Genetics 147: 915-925.

587 Galbusera, P., Githiru, M., Lens, L. and Matthysen, E. 2004. Genetic equilibrium despite habitat 588 fragmentation in an Afrotropical bird. - Mol. Ecol. 13: 1409-1421.

590 Garza, J. C. and Williamson, E. G. 2001. Detection of reduction in population size using data from 591 microsatellite loci. - Mol. Ecol. 10: 305-318.

593 Gibbs, H. L., Tabak, L. M. and Hobson, K. 1999. Characterization of microsatellite DNA loci for a 594 neotropical migrant songbird, the Swainson's thrush (Catharus ustulatus). - Mol. Ecol. 8: 15515951552. 
597 Gill, F. B., Mostrom, A. M. and Mack, A. L. 1993. Speciation in North American chickadees: I.

598 Patterns of mtDNA genetic divergence. - Evolution 47: 195-212.

600 Goldstein, D. B., Linares, A. R., Cavalli-Sforza, L. L. and Feldman, M. W. 1995. An evaluation of 601 genetic distances for use with microsatellite loci. - Genetics 139: 463-471.

602

603 Goudet, J. 1995. FSTAT: a computer program to calculate F-statistics. - J. Hered. 86: 485-486.

604

605 Griffith, S. C., Stewart, I. R. K., Dawson, D. A., Owens, I. P. F. and Burke, T. 1999. Contrasting 606 levels of extra-pair paternity in mainland and island populations of the house sparrow (Passer 607 domesticus): is there an 'island effect'? - Biol. J. Linn. Soc. 68: 303-316.

608

609 Hall, T. A. 1999. BioEdit: a user-friendly biological sequence alignment editor and analysis 610 program for Windows 95/98/NT. - Nucl. Acids Symp. Ser. 41: 95-98.

611

612 Hansson, B., Bensch, S., Hasselquist, D., Lillandt, B. G., Wennerberg, L. and Von Schantz, T. 2000.

613 Increase of genetic variation over time in a recently founded population of great reed warblers 614 (Acrocephalus arundinaceus) revealed by microsatellites and DNS fingerprinting. - Mol. Ecol. 9: $615 \quad 1529-1538$

617 Hansson, B., Bensch, S., Hasselquist, D. and Nielsen, B. 2002. Restricted dispersal in a long618 distance migrant bird with patchy distribution, the great reed warbler. - Oecologia 130: 536-542. 619

620 Hansson, B., Hasselquist, D., Tarka, M., Zehtindjiev, P. and Bensch, S. 2008. Postglacial 
colonisation patterns and the role of isolation and expansion in driving diversification in a passerine

622 bird. - PloS ONE 3: e2794.

623

624 Hardy, O. J. and Vekemans, X. 2002. SPAGeDi: a versatile computer program to analyze spatial 625 genetic structure at individual or population level. - Mol. Ecol. Not. 2: 618-620.

627 Hebert, P. D. N., Stoeckle, M. Y., Zemlak, T. S. and Francis, C. M. 2004. Identification of Birds 628 through DNA Barcodes. - PloS Biol. 2: 1657-1688.

629

630 Hewitt, G. 2000. The genetic legacy of the Quaternary ice ages. - Nature 405: 907-913.

631

632 Hewitt, G. M. 2004. Genetic consequences of climatic oscillations in the Quaternary. - Proc. R. Soc. 633 B 359: 183-195.

634

635 Jiguet, F., Rguibi-Idrissi, H. and Provost, P. 2010. Undescribed reed warbler breeding in Morocco. 636 Dutch Birding 32: 29-36.

638 Kennerley, P. and Pearson, D. 2010. Reed and Bush Warblers. - Christopher Helm Publishers Ltd.

640 Kerr, K. C .R., Stoeckle, M. Y., Dove, C. J., Weigt, L. A., Francis, C. M. and Hebert, P. D. N. 2007. 641 Comprehensive DNA barcode coverage of North American birds. - Mol. Ecol. Not. 7: 535-543.

643 Kimura, M. 1980. A simple method for estimating evolutionary rate of base substitution through 644 comparative studies of nucleotide sequences. - J. Mol. Evol. 16: 111-120. 
646 Koenig, W. D., Van Vuren, D. and Hooge, P. N. 1996. Detectability, philopatry, and the distribution 647 of dispersal distances in vertebrates. - Trends Ecol. Evol. 11: 514-517.

648

649 Kralj, J., Procházka, P., Fainová, D., Patzenhauerová, H. and Tutiš, V. 2010. Intraspecific variation 650 in the wing shape and genetic differentiation of reed warblers Acrocephalus scirpaceus in Croatia. 651 Acta Ornithol. 45: 51-58.

652

653 Kvist, L., Ponnikas, S., Belda, E. J., Encabo, I., Martínez, E., Onrubia, A., Hernández, J. M., Vera, 654 P., Neto, J. M. and Monrós, J. S. 2011. Endangered subspecies of the Reed Bunting (Emberiza 655 schoeniclus witherby and E. s. lusitanica) in Iberian Peninsula have different genetic structures. - J. 656 Ornithol. 152: 681-693.

658 Laurence, W. F. 2010. Habitat destruction: death by a thousand cuts. - In: Sohdi, N. S. and Ehrlich, P. R. (ed.), Conservation Biology for All. Oxford University Press, pp. 73-87.

660

Librado, P. and Rozas, J. 2009. DnaSP v5: a software for comprehensive analysis of DNA 662 polymorphism data. - Bioinformatics 25: 1451-1452.

663

664 Loiselle, B. A., Sork, V. L., Nason, J. and Graham, C. 1995. Spatial genetic structure of a tropical understory shrub, Psychotria officinalis (Rubiaceae). - Am. J. Bot. 82: 1420-1425.

667 Lovette, I. J., Bermingham, E., Seutin, G. and Ricklefs, R. E. 1998. Evolutionary differentiation in 668 three endemic West Indian warblers. - Auk 115: 890-903.

670 Martínez, J. G., Soler, J. J., Soler, M., Møller, A. P. and Burke, T. 1999. Comparative population 
671 structure and gene flow of a brood parasite, the great spotted cuckoo (Clamator glandarius), and its

672 primary host, the magpie (Pica pica). - Evolution 53: 269-278.

673

674 Matthysen, E., Lens, L., Van Dongen, S., Verheyen, G. R., Wauters, L. A., Adriaensen, F. and

675 Dhondt, A. A. 1995. Diverse effects of forest fragmentation on a number of animal species. - Belg.

676 J. Zool. 125: 175-183.

677

678 Murray Gates, D. 1993. Climate Change and its Biological Consequences. - Sinauer Associates.

679

680 Neto, J. M., Arroyo, J. L., Bargain, B., Monrós, J. S., Mátrai, N., Procházka, P. and Zehtindjiev, P. 681 2012. Phylogeography of a Habitat Specialist with High Dispersal Capability: The Savi’s Warbler 682 Locustella luscinioides. - PloS ONE 7: e38497.

683

684 Neumann, K. and Wetton, J. H. 1996. Highly polymorphic microsatellites in the house sparrow 685 Passer domesticus. - Mol. Ecol. 5: 307-309.

686

687 Newton, I. 1998. Population Limitation in Birds. - Academic Press.

688

689 Noon, B. R. and Sauer, J. R. 1992. Population models for passerine birds: structure, 690 parametrization, and analysis. - In: McCullough, D. R. and Barrett, R. (ed.), Wildlife 2001: 691 populations. Elsevier Applied Sciences, pp. 441-464.

692

693 Norberg, U. M. 1989. Vertebrate Flight, Mechanics, Physiology, Morphology, Ecology and 694 Evolution. - Springer-Berlag. 
696 Paracuellos, M. and Tellería, J. L. 2004. Factors affecting the distribution of a waterbird

697 community: the role of habitat configuration and bird abundance. - Waterbirds 27: 446-453.

698

699 Paetaku, D., Slade, R., Burden, M. and Estoup, A. 2004. Genetic assignment methods for the direct, 700 real-time estimation of migration rate: a simulation-based exploration of accuracy and power. - Mol. 701 Ecol. 13: 55-65.

702

703 Paradis, E., Baillie, S. R., Sutherland, W. J. and Gregory, R. D. 1998. Patterns of natal and breeding 704 dispersal in birds. - J. Anim. Ecol. 67: 518-536.

705

706 Peiró, I. G. 2003. Intraspecific variation in the wing shape of the long-distance migrant reed warbler 707 Acrocephalus scirpaceus: effects of age and distance of migration. - Ardeola 50: 31-37.

709 Petren, K. 1998. Microsatellite primers from Geospiza fortis and cross-species amplification in 710 Darwin's finches. - Mol. Ecol. 7: 1782-1784.

712 Piry, S., Alapetite, A., Cornuet, J. M., Paetaku, D., Baudouin, L. and Estoup, A. 2004. 713 GENECLASS2: a software for genetic assignment and first-generation migrant detection. - J. 714 Hered. 95: 536-539.

716 Piry, S., Luikart, G. and Cornuet, J. M. 1999. BOTTLENECK: a computer program for detecting 717 recent reductions in the effective population size using allele frequency data. - J. Hered. 95: 536718539.

720 Pritchard, J. K., Stephens, M. and Donnelly, P. 2000. Inference of population structure using 
multilocus genotype data. - Genetics 155: 945-959.

722

723 Procházka, P., Bellinvia, E., Fainová, D., Hájková, P., Elhalah, A. and Alomari, K. 2008.

724 Immigration as a possible rescue of a reduced population of a long-distant migratory bird: Reed 725 warblers in the Azraq Oasis, Jordan. - J. Arid Environ. 72: 1184-1192.

727 Procházka, P., Hobson, K. A., Karcza, Z. and Kralj, J. 2008. Birds of a feather winter together: 728 migratory connectivity in the reed warbler Acrocephalus scirpaceus. - J. Ornithol. 149: 141-150.

730 Procházka, P., Stokke B. G., Jensen, H., Fainová, D., Bellinvia, D., Fossøy, Vikan J. R., Bryja, J. 731 and Soler, M. 2011. Low genetic differentiation among reed warbler Acrocephalus scirpaceus 732 populations across Europe. - J. Avian Biol. 42: 103-113.

734 Rannala, B. and Mountain, J. L. 1997. Detecting immigration by using multilocus genotypes. 735 Proc. Natl. Acad. Sci. USA 94: 9197-9201.

737 Raymond, M. and Rousset, F. 1995. GENEPOP (version 1.2): population genetic software for exact 738 tests and ecumenism. - J. Hered. 86: 248-249.

740 Richardson, D. S., Jury, F. L., Dawson, D. A., Salgueiro, P., Komdeur, J. and Burke, T. 2000. Fifty

741 Seychelles warbler (Acrocephalus sechellensis) microsatellite loci polymorphicin Sylvidae species 742 and their cross-species amplification in other passerine birds. - Mol. Ecol. 9: 2225-2230.

744 Rogers, A. R. and Harpending, H. 1992. Population growth makes waves in the distribution of 745 pairwise genetic differences. - Mol. Biol. Evol. 9: 552-569. 
747 Rousset, F. 2008. genepop'007: a complete re-implementation of the genepop software for Windows 748 and Linux. - Mol. Ecol. Resour. 8: 103-106.

749

750 Silva, J. P., Phillips, L., Jones, W., Eldridge, J. and O'Hara, E. 2007. Life and Europe's wetlands, 751 restoring a vital ecosystem. - Office for Official Publications of the European Communities.

753 Taberlet, P., Fumagalli, L., Wust-Saucy, A. G. and Cosson J. F. 1998. Comparative phylogeography 754 and postglacial colonization routes in Europe. - Mol. Ecol. 7: 453-464.

756 Tajima, F. 1989. Statistical method for testing the neutral mutation hypothesis by DNA 757 polymorphism. - Genetics 123: 585-595.

759 Vadász, C., Német, Á., Karcza, Z., Loránt, M., Biró, C. and Csörgő, T. 2008. Study on breeding site

760 fidelity of Acrocephalus Warblers in Central Hungary. - Acta Zool. Acad. Sci. Hung. 54 (Suppl. 1): $761 \quad 167: 175$

763 Van Oosterhout, C. V., Hutchinson, W. F. and Wills, D. P. M. 2004. MICROCHECKER: software 764 for identifying and correcting genotyping errors in microsatellite data. - Mol. Ecol. Not. 4: 535: 765538.

767 Van Vessem, J., Hecker, N. and Tucker, G. M. 1997. Inland wetlands. - In: Tucker, G. M. and Evans, 768 M. I. (ed.), Habitats for birds in Europe: A conservation strategy for the wider environment. 769 BirdLife Conservation Series 6. BirdLife International, pp. 125-158. 
771 Wright, H. E., Kutzbach, J. E., Webb, T., Ruddiman, W. F., Street-Perrott, F. A. and Bairlein, P. J.

772 1993. Global Climates since the Last Glacial Maximum. - University of Minnesota Press. 
Table 1. Sample sizes, expected heterozygosity $\left(\mathrm{H}_{\mathrm{e}}\right)$, allelic richness (A), inbreeding coefficient $\left(F_{I S}\right)$, Wilcoxon $\mathrm{p}$ - values (Wil. Test, one-tailed for heterozygosity excess) and Garza-Williamson index (G-W) of (a) reed warbler and (b) moustached warbler, calculated from microsatellite data for each sampling site and populations defined by STRUCTURE (Str).

a)

\begin{tabular}{lcccccc}
\hline Sample & $\mathrm{N}$ & $\mathrm{H}_{\mathrm{e}}(\mathrm{SD})$ & $\mathrm{A}(\mathrm{SD})$ & $\mathrm{F}_{\mathrm{IS}}(\mathrm{SD})$ & $\mathrm{P}$ (Wil. Test) & $\mathrm{G}-\mathrm{W}$ \\
\hline Larache & 38 & $0.696(0.316)$ & $1.70(0.32)$ & $0.127(0.314)$ & 0.207 & 0.84 \\
Pego-Oliva & 7 & $0.681(0.366)$ & $1.68(0.37)$ & $0.049(0.281)$ & & 0.67 \\
Mallorca & 3 & $0.650(0.375)$ & $1.65(0.38)$ & $-0.153(0.413)$ & & 0.62 \\
Villafranca & 20 & $0.710(0.249)$ & $1.71(0.25)$ & $-0.022(0.257)$ & 0.661 & 0.73 \\
Total & 68 & $0.716(0.272)$ & 1.68 & $0.014(0.316)$ & & 1.00 \\
\hline
\end{tabular}

b)

\begin{tabular}{lcccccc}
\hline Sample & $\mathrm{N}$ & $\mathrm{H}_{\mathrm{e}}(\mathrm{SD})$ & $\mathrm{A}(\mathrm{SD})$ & $\mathrm{F}_{\mathrm{IS}}(\mathrm{SD})$ & $\mathrm{P}$ (Wil. Test) & $\mathrm{G}-\mathrm{W}$ \\
\hline Pego-Oliva & 30 & $0.602(0.184)$ & $3.76(2.16)$ & $-0.275(0.404)$ & 0.078 & 0.96 \\
Villafranca & 9 & $0.590(0.185)$ & $3.47(2.22)$ & $-0.344(0.477)$ & 0.078 & 0.85 \\
Mallorca & 15 & $0.538(0.202)$ & $2.96(1.60)$ & $-0.500(0.454)$ & 0.023 & 0.82 \\
& & & & & & \\
(= Str - Mallorca) & & & & & & \\
Str - Spanish mainland & 39 & $0.611(0.172)$ & $4.28(3.01)$ & $-0.240(0.394)$ & 0.039 & 0.96 \\
Total & 54 & $0.621(0.182)$ & 3.40 & $-0.250(0.115)$ & & 0.88 \\
\hline
\end{tabular}


Table 2. Pairwise $F_{\mathrm{ST}}$ values ( $p$-values in parentheses) between sampling sites and between STRUCTURE (Str) populations of (a) reed warbler and (b) moustached warbler, calculated from microsatellite data.

a)

\begin{tabular}{lccc}
\hline Sample & Pego-Oliva & Mallorca & Villafranca \\
\hline Mallorca & $0.0030(0.189)$ & - & - \\
Villafranca & $-0.0211(0.505)$ & $0.0732(0.018)$ & - \\
Larache & $0.0189(0.027)$ & $-0.0029(0.351)$ & $-0.0193(0.892)$ \\
\hline
\end{tabular}

b)

\begin{tabular}{lcc}
\hline Sample & Pego-Oliva & Mallorca (= Str - Mallorca) \\
\hline Mallorca & $0.1146(0.000)$ & - \\
Villafranca & $0.0609(0.000)$ & $0.1352(0.000)$ \\
Str - Spanish mainland & - & $0.1078(0.000)$ \\
\hline
\end{tabular}


Table 3. Assignment of (a) reed warblers and (b) moustached warblers to the sampling sites and the STRUCTURE (Str) populations, on the basis of microsatellite data; individuals which have not been assigned to their site/population of origin are reported in bold.

a)

\begin{tabular}{lcccc}
\hline & Assigned to & & & \\
\cline { 2 - 5 } Sampling site of origin & Larache & Pego-Oliva & Mallorca & Villafranca \\
Larache & 35 & $\mathbf{1}$ & 0 & $\mathbf{2}$ \\
Pego-Oliva & $\mathbf{3}$ & 0 & 0 & $\mathbf{4}$ \\
Mallorca & $\mathbf{2}$ & 0 & 0 & $\mathbf{1}$ \\
Villafranca & $\mathbf{1 2}$ & 0 & 0 & 8 \\
\hline
\end{tabular}

b)

\begin{tabular}{lccc}
\hline & Assigned to & & \\
\cline { 2 - 4 } Sampling site of origin & Pego-Oliva & Mallorca & Villafranca \\
Pego-Oliva & 30 & 0 & 0 \\
Mallorca & $\mathbf{5}$ & 9 & $\mathbf{1}$ \\
Villafranca & $\mathbf{6}$ & 0 & 3 \\
& Assigned to & & \\
Str population of origin & Str - Spanish mainland & Str - Mallorca \\
Str - Spanish mainland & 39 & 0 & \\
Str - Mallorca & $\mathbf{6}$ & 9 & \\
\hline
\end{tabular}


Table 4. Sample sizes, number of segregating sites, number of haplotypes, haplotype diversity (h) and nucleotide diversity $(\pi)$ of (a) reed warbler and (b) moustached warbler, calculated from mitochondrial DNA data for each sampling site and STRUCTURE (Str) population (Str populations were identified on the basis of microsatellite data).

a)

\begin{tabular}{lccccc}
\hline Sample & $\mathrm{N}$ & N segregating sites & N haplotypes & $\mathrm{h}$ & $\pi$ \\
\hline Larache & 29 & 21 & 13 & 0.823 & 0.004 \\
Pego-Oliva & 5 & 11 & 3 & 0.700 & 0.010 \\
Mallorca & 3 & 0 & 1 & 0.000 & 0.000 \\
Villafranca & 13 & 14 & 6 & 0.718 & 0.008 \\
Total & 50 & 23 & 18 & 0.745 & 0.006 \\
\hline
\end{tabular}

b)

\begin{tabular}{lccccc}
\hline Sample & $\mathrm{N}$ & N segregating sites & $\mathrm{N}$ haplotypes & $\mathrm{h}$ & $\pi$ \\
\hline Pego-Oliva & 22 & 3 & 4 & 0.333 & 0.001 \\
Villafranca & 8 & 0 & 1 & 0.000 & 0.000 \\
Mallorca & 13 & 4 & 4 & 0.526 & 0.001 \\
& & & & & \\
(= Str - Mallorca) & & 3 & 4 & 0.251 & 0.000 \\
Str - Spanish mainland & 30 & 7 & 7 & 0.339 & 0.001 \\
Total & 43 & & &
\end{tabular}


Table 5. Pairwise $\phi_{\text {ST }}$ values ( $p$-values in parentheses) between sampling sites and between STRUCTURE (Str) populations of (a) reed warbler and (b) moustached warbler, calculated from mitochondrial DNA data. STRUCTURE population were identified on the basis of microsatellite data.

a)

\begin{tabular}{lccc}
\hline Sample & Pego-Oliva & Mallorca & Villafranca \\
\hline Mallorca & $-0.0918(0.802)$ & - & - \\
Villafranca & $-0.0997(0.685)$ & $-0.1149(0.991)$ & - \\
Larache & $0.0486(0.207)$ & $-0.1742(0.991)$ & $0.0302(0.072)$ \\
\hline
\end{tabular}

b)

\begin{tabular}{lcc}
\hline Sample & Pego-Oliva & Mallorca (= Str - Mallorca) \\
\hline Mallorca & $0.0660(0.036)$ & - \\
Villafranca & $-0.0402(0.739)$ & $0.0065(0.541)$ \\
Str - Spanish mainland & - & $0.0862(0.000)$ \\
\hline
\end{tabular}




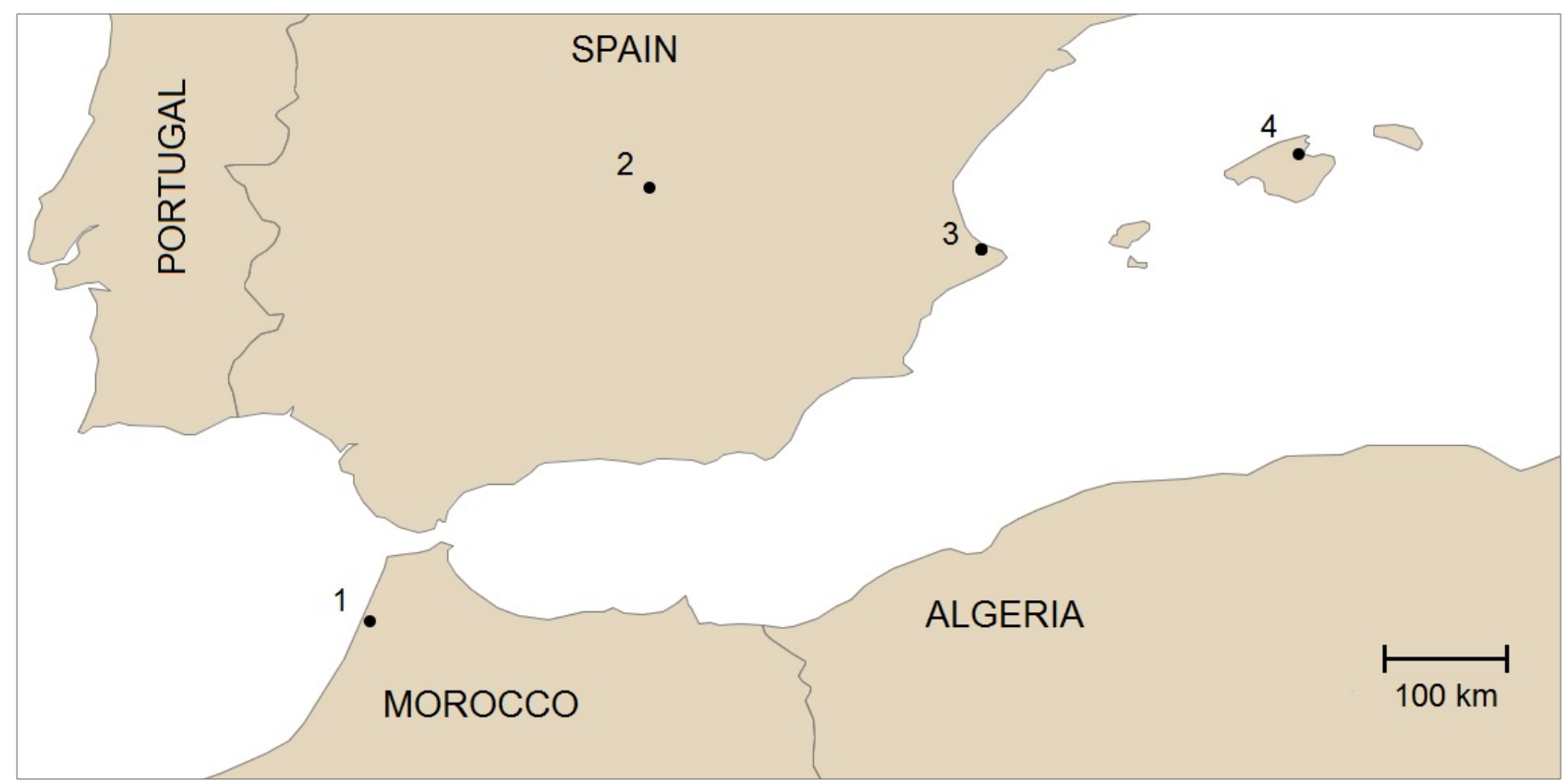

Figure 1. Location of the sampling sites: 1) Larache, 2) Villafranca de los Caballeros, 3) Pego-Oliva Natural Park and 4) S'Albufera de Mallorca. 
a)

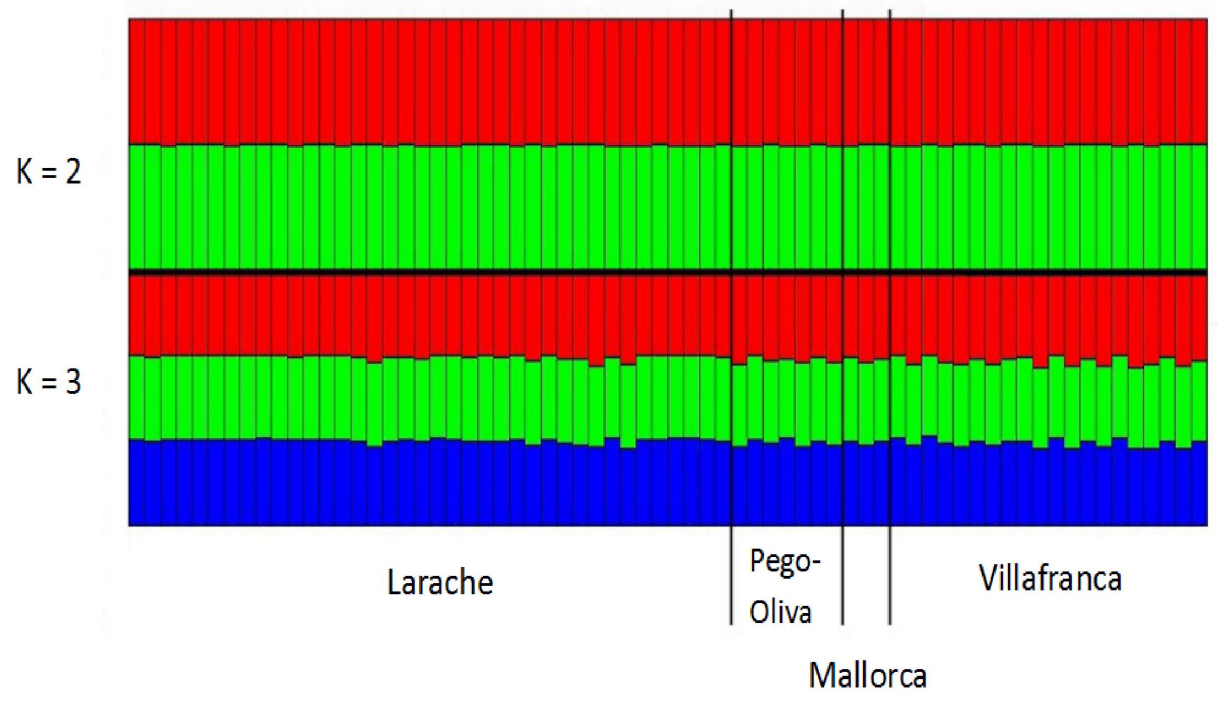

b)

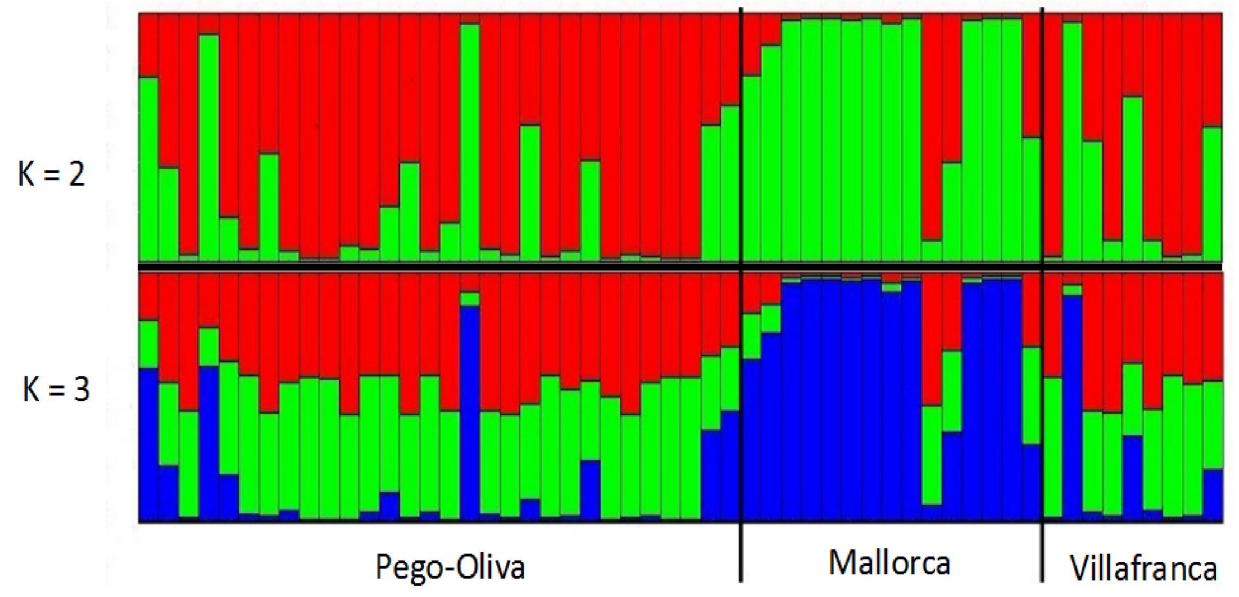

Figure 2. Bar plots of the STRUCTURE results based microsatellite data of (a) reed warbler and (b) moustached warbler for $\mathrm{K}=2$ and $\mathrm{K}=3$. Each column corresponds to an individual and represents its probability to belong to one of the $\mathrm{K}$ clusters. 


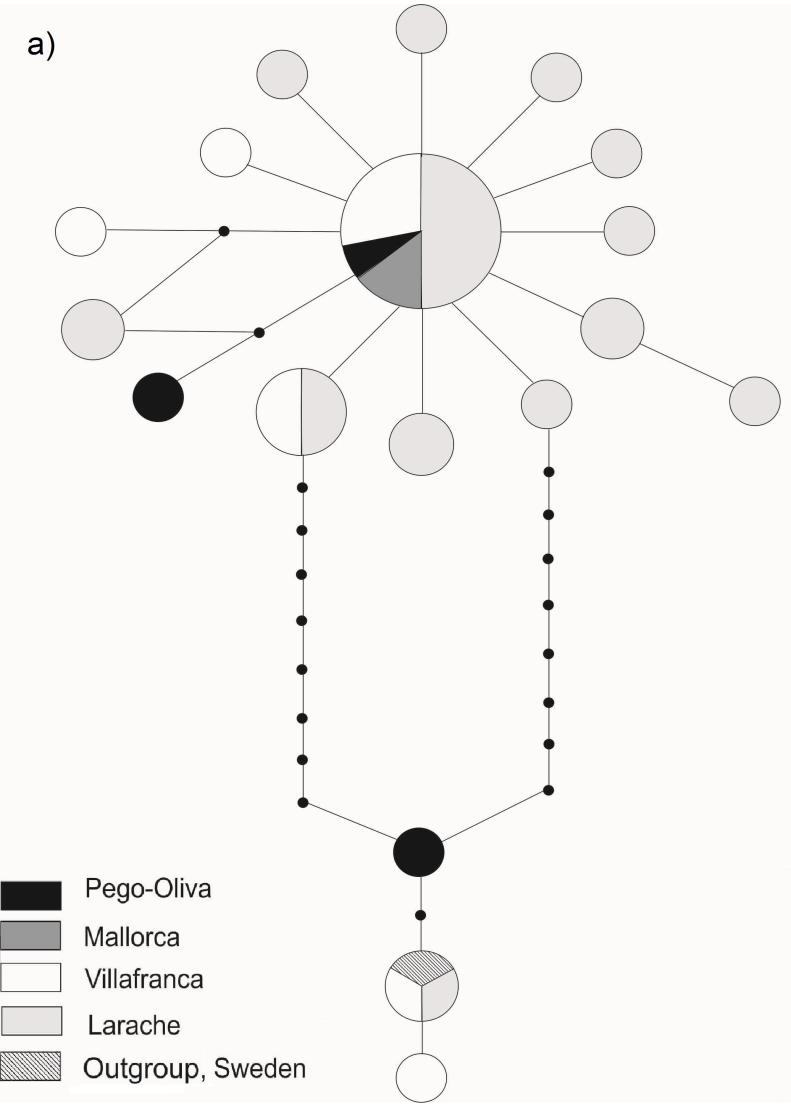

b)

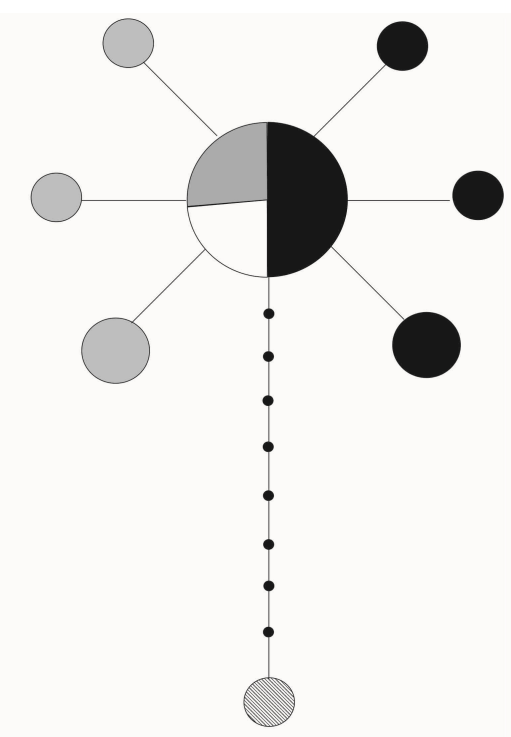

Figure 3. Statistical parsimony network based on (a) reed warbler and (b) moustached warbler mtDNA data. Each haplotype is represented by a circle, whose area is proportional to the number of individuals belonging to the haplotype. Each connecting bar stands for one substitution. 


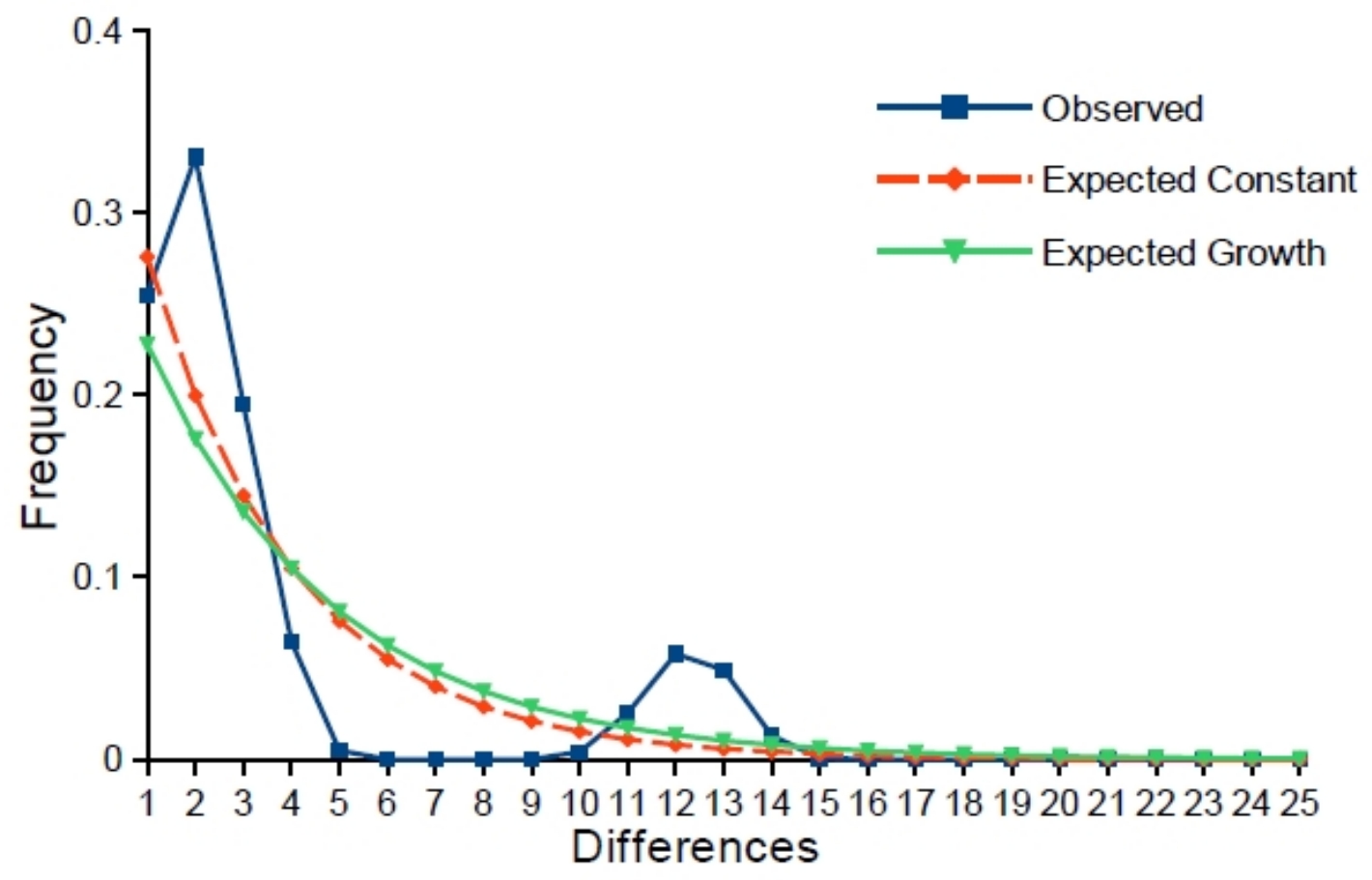

Figure 4. Mismatch distributions calculated over the whole reed warbler sample using mitochondrial DNA data. The bimodal shape of the observed frequencies indicates a past admixture of two previously isolated populations. 
Scenario $\mathrm{A}$

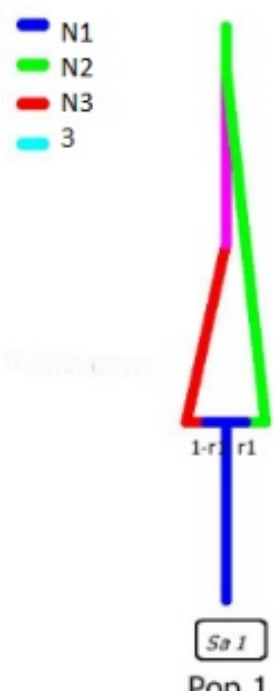

N1 514000 (107000-962000)

N2 173000 (43500-687000)

N3 487000 (61500-942000)

ta 5690 (583-9610)

t2 12200 (5490-17900)

t3 15700 (2480-19800)
Scenario B

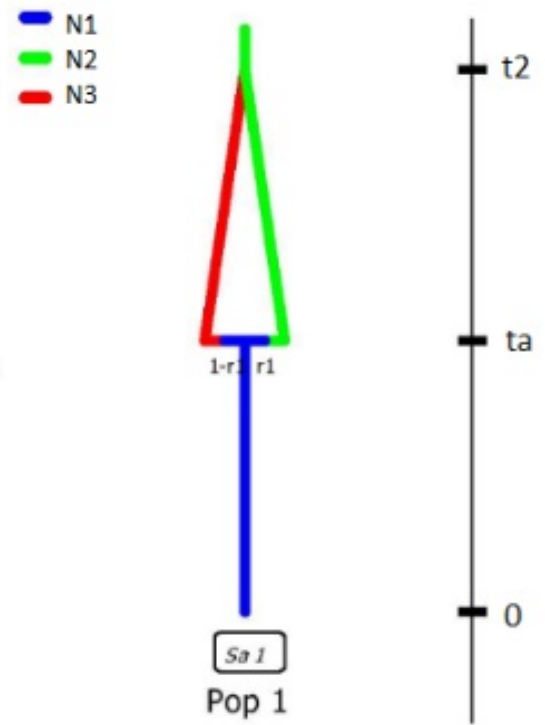

N1 668000 (239000-968000)

N2 134000 (29700-628000)

N3 466000 (588000-944000)

ta 4750 (505-9420)

t2 13100 (4700-19300)

Figure 5. Demographic history of reed warbler according to the two best DIY ABC scenarios obtained from mitochondrial DNA data. The parameters estimates are provided as median $(95 \% \mathrm{CI})$ and include the current (N1) and the ancient (N2, N3) effective population size, and timing (in terms of generations) of the admixture event (ta), population size variation ( $\mathrm{t} 2$ scenario A) and population divergence ( $\mathrm{t} 3$ scenario $\mathrm{A}, \mathrm{t} 2$ scenario $\mathrm{B})$. 


$$
\begin{aligned}
& \text { - N1 } \\
& \text { - N2 } \\
& \text { - Na }
\end{aligned}
$$
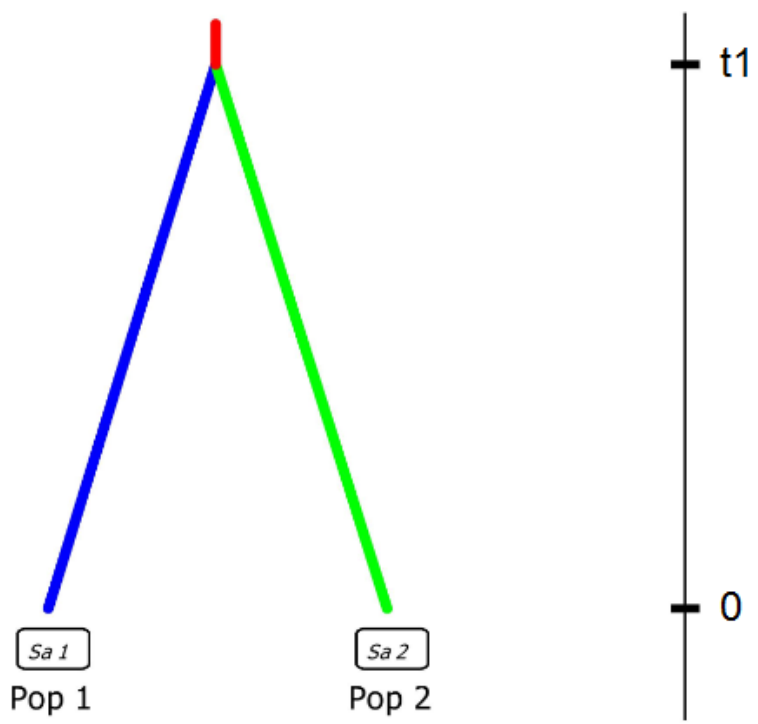

Figure 6. Demographic history of moustached warbler: best DIY ABC scenario obtained from microsatellite data. Divergence time (t1) of the two STRUCTURE populations (Pop 1 - Spanish mainland and Pop 2 - Mallorca) has been estimated to be 230 generations (95\% CI 41 - 449). 